\title{
Satisfaction and Workload of Slovenian Teachers during Distance Learning
}

\author{
Vesna Trančar* \\ PhD., High school teacher at $\check{S} C$ Ptuj, Slovenia
}

*Corresponding Author: Vesna Trančar, PhD., High school teacher at ŠC Ptuj, Slovenia

\begin{abstract}
This paper presents an analysis of the results of the survey on teacher satisfaction and workload during distance learning. It points out the exclusive workload of teachers during distance learning, as teachers are often pushed into the background, this time as well, their work, workload and efforts are not taken into consideration, or their work is taken for granted. The purpose of the survey is to find out how teachers felt during distance learning. The results of the research will help to find solutions for a better and higher quality organization of distance learning in the future.
\end{abstract}

Keywords: distance learning, teacher workload, opinions and suggestions of surveyed teachers

\section{INTRODUCTION}

Since the coronavirus pandemic (COVID-19) has paralyzed life around the world, teachers have been struggling to transform their physical classrooms into virtual or even hybrid ones and pupils have been getting used to new methods of acquiring knowledge in online learning environments. At the beginning of the first, and later, of the novel wave of the epidemic, neither teachers nor pupils knew when exactly they would becoming back from school with their books and other teaching aids. They rather faced even more stressful period than they could have ever imagined.

Students and pupils (hereinafter: pupils), especially in the beginning of distance learning, were feeling stressed and at the same time disconnected. So were, if not even more, the teachers. The additional efforts that teachers and professors (hereinafter: teachers) have faced in distance learning are strong physical and emotional strain. Foreign sources are reporting that teachers are working twice as hard during the COVID-19 pandemic and that they are feeling constantly overloaded and dissatisfied.

As a high school teacher, I experienced the first wave of the COVID-19 pandemic in a similar way. Sitting at a computer for more than ten hours a day, giving written instructions to pupils, keeping records of inactive pupils, reporting inactive pupils to classmates and school counselling, analysing pupils' progress, checking pupils' assignments in online classrooms, being available to pupils on Saturdays, Sundays and during the holidays, the workload and exhaustion were intensified by additional tasks on the part of the school management.

\section{RESEARCH GOALS}

Distance learning has brought teachers new experiences and new challenges. Just like the pupils, the teachers are also experiencing additional burden. The goal of this research is to find out how teachers are feeling during distance learning and what changes would they like to see in case this situation happens again in the future. The results of the research will be presented, challenging the entire education system, to the representatives of the Ministry of Education, Science and Culture.

\subsection{Survey Questionnaire}

The author sent an anonymous survey questionnaire to primary and secondary schools. The publicly available online school address database was used. The survey was opened from 22 December 2020 to 17 January 2021.

The survey included eight questions, matrix-type questions, A-B-C answered questions, two grading scale questions, and the last two optional questions allowing respondents to write down their initiatives, opinions, comments, and suggestions. 


\subsection{Survey Results and Interpretation}

The survey included a total of 416 respondents. $37.7 \%$ of all respondents teach at primary schools, $27.6 \%$ of respondents teach at secondary schools, $1.2 \%$ of respondents combine classes at secondary, primary school or college and university, and $0.5 \%$ of respondents teach only at a college or university.

To the question "To what extent do you agree with the following answers regarding distance learning?" Respondents were able to choose between three answers: I totally agree, neither agree nor disagree, disagree at all. The results showed that $42.4 \%$ of respondents were well prepared for distance learning, $9.4 \%$ of respondents answered negatively to this question, and $48.2 \%$ were undecided, as shown in Figure 1.

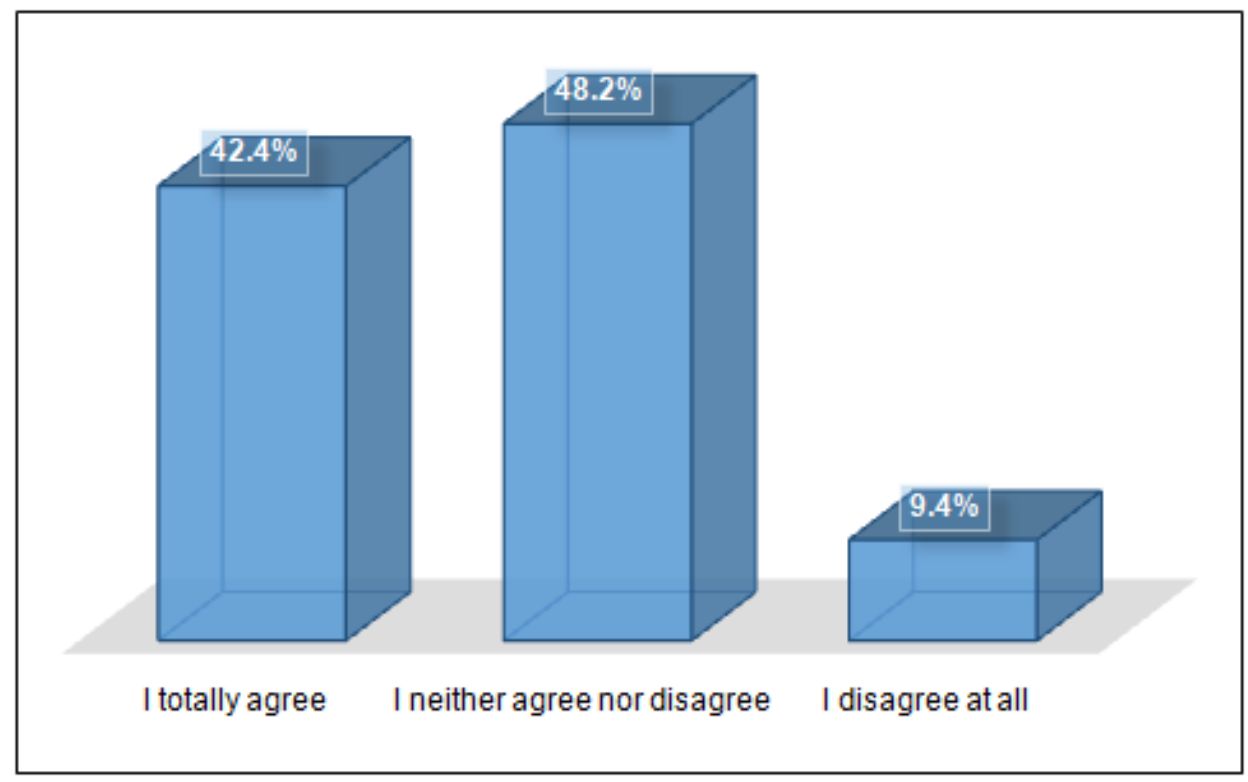

Figure1. I was well prepared for distance learning.

$61.2 \%$ of respondents completely agreed with the answer "I had everything I needed for distance learning: computer, camera, speakers, suitable space", $9.1 \%$ of respondents gave negative answers (they did not agree with the answer at all), $29.7 \%$ of respondents remained undecided, or neither agreed nor disagreed with the answer (Figure 2).

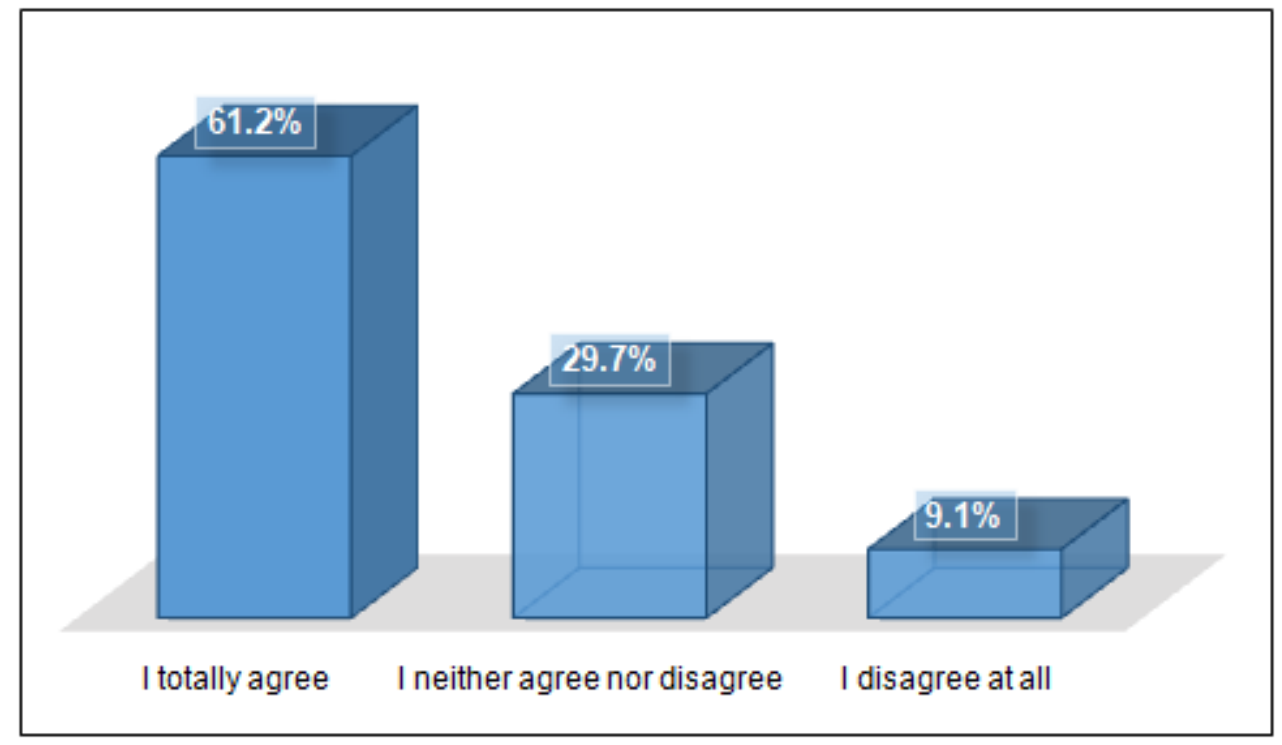

Figure2. I had everything I needed for distance learning.

With the answer "Even before I started distance learning, I had received all the necessary instructions from the school management for the use of the distance learning application (MS Teams, Google Meet, Arnes Zoom...)" 63.8\% of respondents fully agreed, $8.6 \%$ of respondents did not agree at all, $27.6 \%$ of respondents remained undecided (Figure 3). 


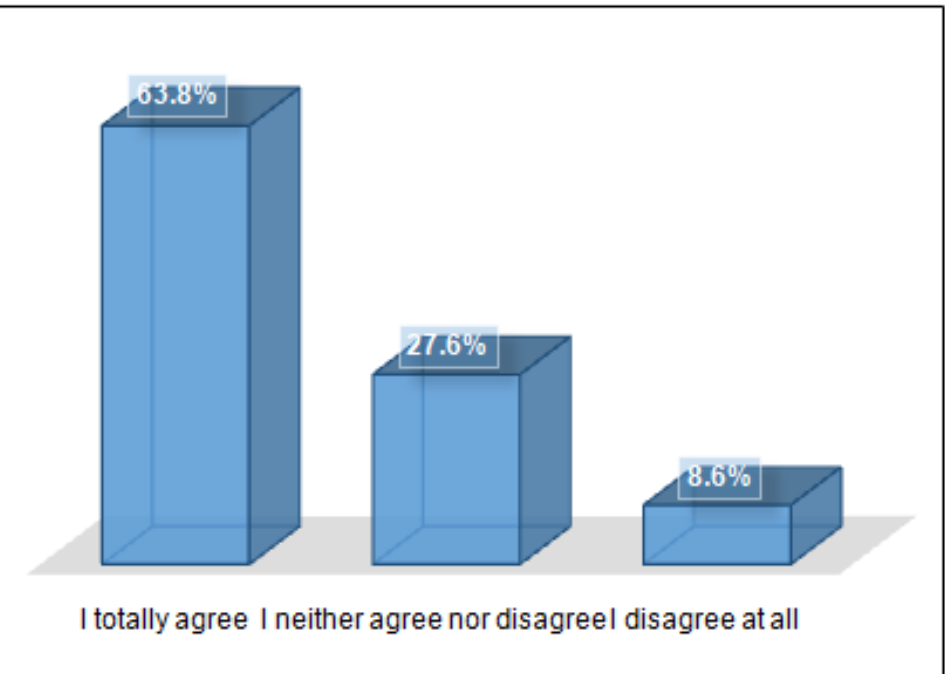

Figure3. Even before I started distance learning, I had received all the necessary instructions from the school management.

$70.6 \%$ of respondents completely agreed with the answer "I received various trainings from the school management (e.g. use of the online classroom)", $6.0 \%$ of respondents did not agree with the answer at all, 23.4\% of respondents remained undecided (Figure 4).

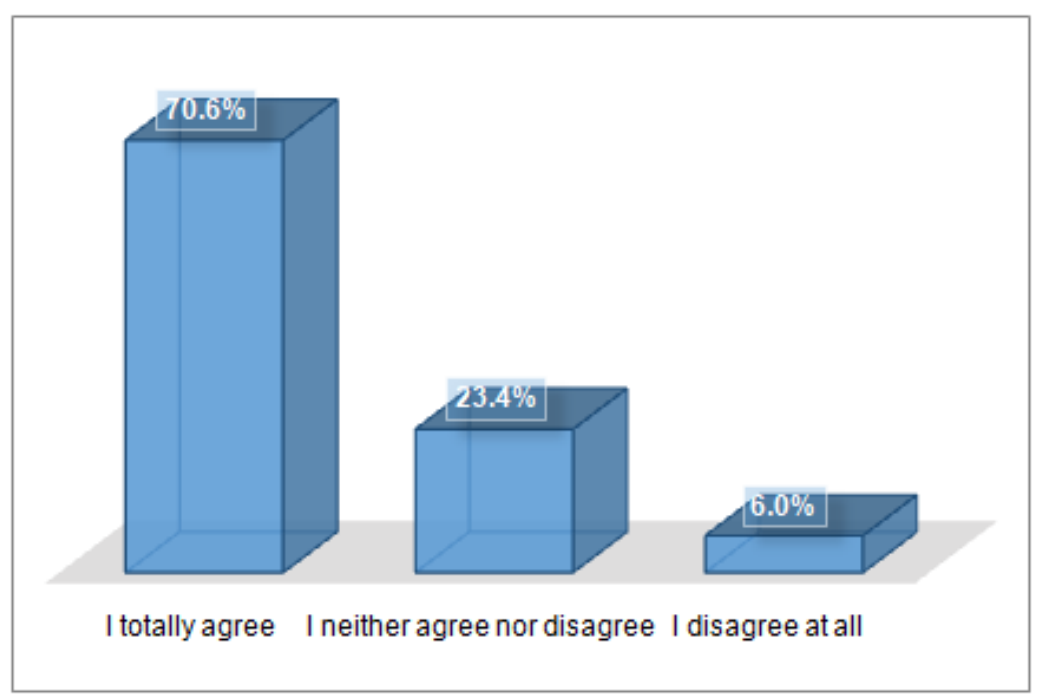

Figure4. I received various trainings from the school management.

$47.4 \%$ of respondents completely agreed with the answer "I had no problems with the distance learning application", $7.6 \%$ of respondents did not agree at all, $45.0 \%$ of respondents remained undecided (Figure 5).

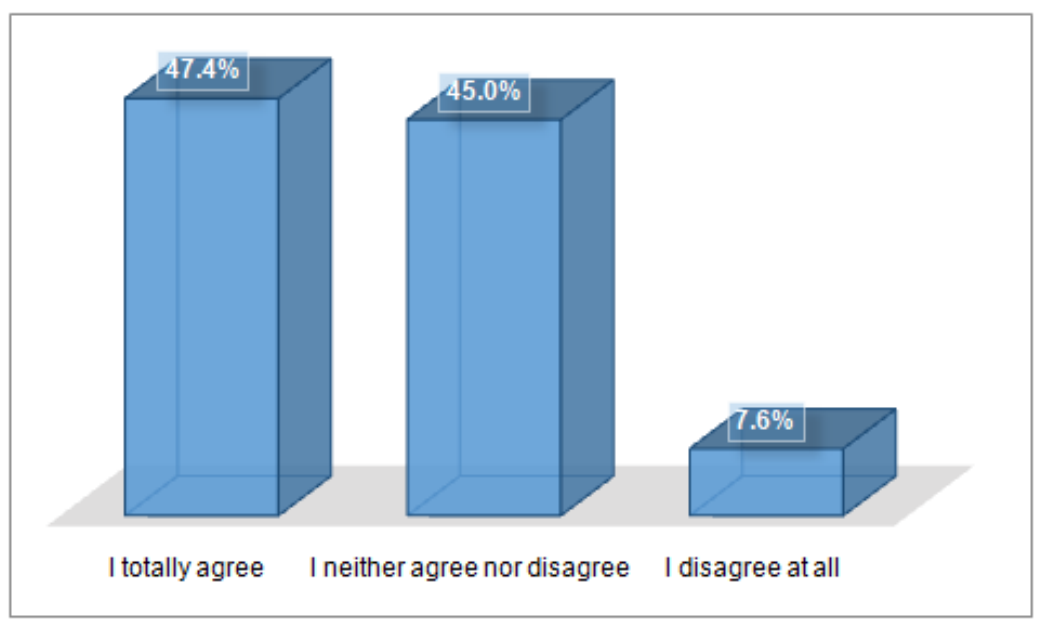

Figure5. I did not have any problems with the distance learning application. 
$31.8 \%$ of respondents completely agreed with the answer "I have achieved the set learning goals with distance learning", $12.0 \%$ of respondents did not agree at all, $56.2 \%$ of respondents remained undecided (Figure 6).

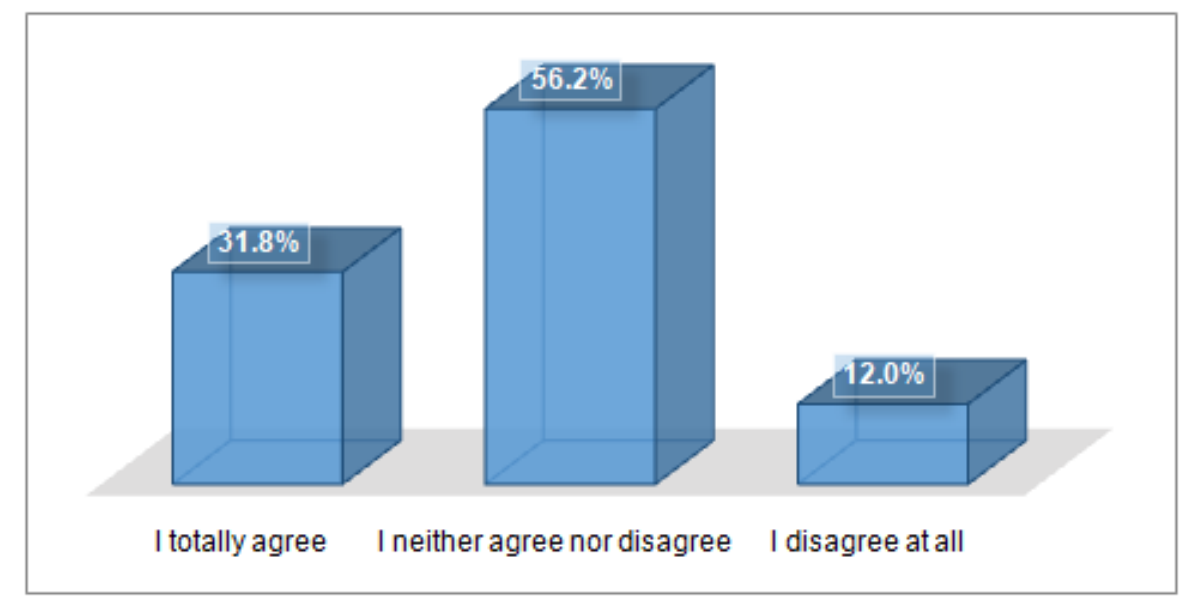

Figure6. I have achieved the set learning goals through distance learning.

$41.4 \%$ of respondents completely agreed with the answer "I have made my work easier by cooperating with other teachers", $17.7 \%$ of respondents gave negative answers, or did not agree with the answer at all, $40.9 \%$ of respondents remained undecided (Figure 7).

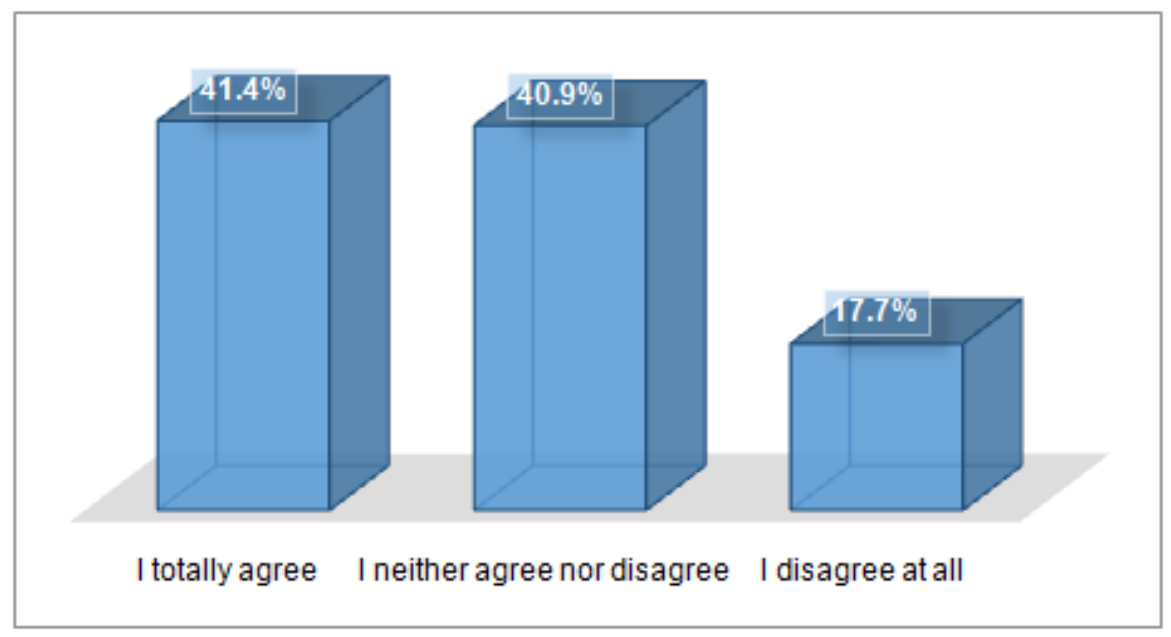

Figure7. I have made my work easier by cooperating with other teachers.

$31.0 \%$ of respondents completely agreed with the answer "I have used cross-curricular connections to make the work easier to the pupils", $19.0 \%$ of respondents gave a negative answer, or disagreed with the answer at all, 50.0\% of respondents remained undecided (Figure 8).

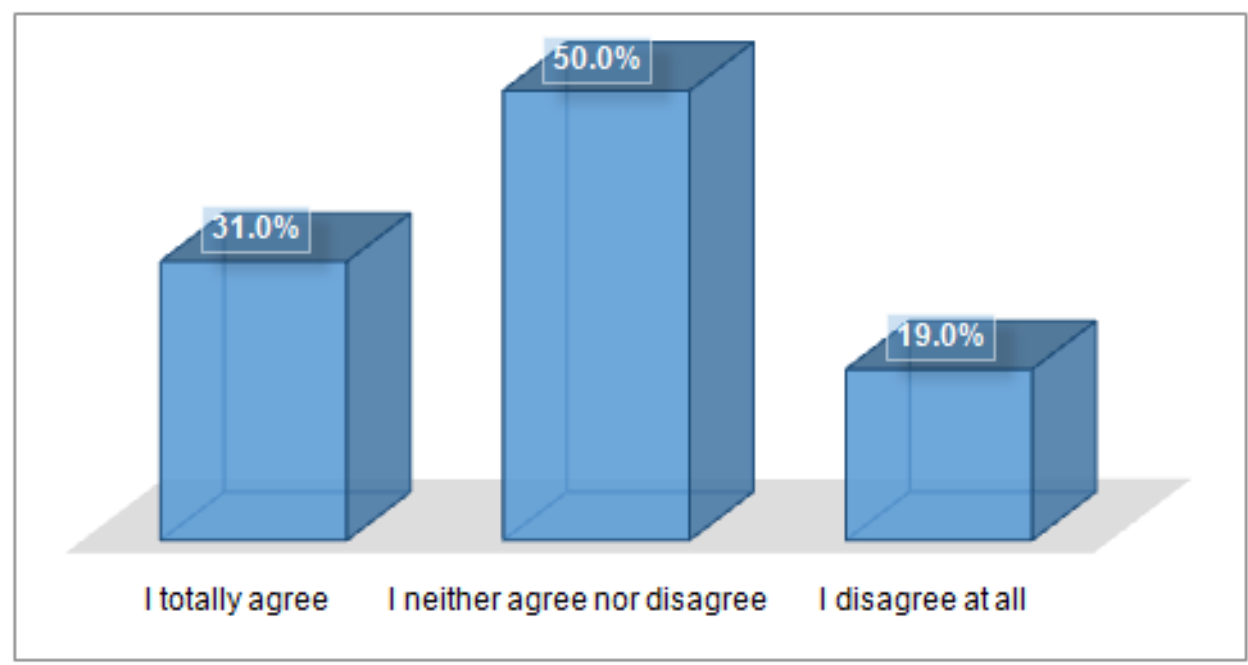

Figure8. I have used cross-curricular connections to make the work easier to the pupils. 
$75.0 \%$ of respondents completely agreed with the answer "In case of problems (substantive or technical) I knew who to consult", $6.8 \%$ of respondents did not agree at all, $18.2 \%$ of respondents were undetermined (Figure 9).

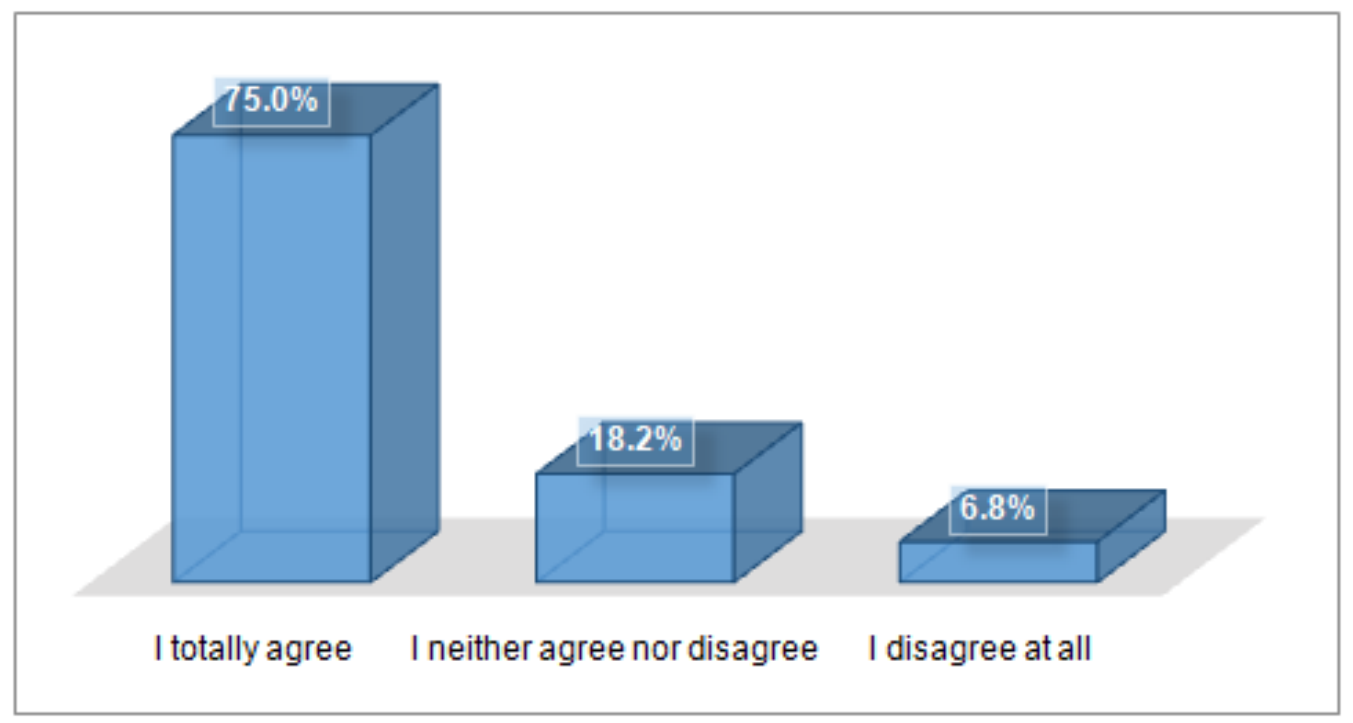

Figure9. In case of problems, I knew who to consult.

$68.8 \%$ of respondents completely agreed with the answer "Compared to the spring term, I conducted the autumn term distance learning much easier", 5.2\% of respondents gave negative answers, or did not agree with the answer at all, 26.0\% of respondents remained undecided (Figure 10).

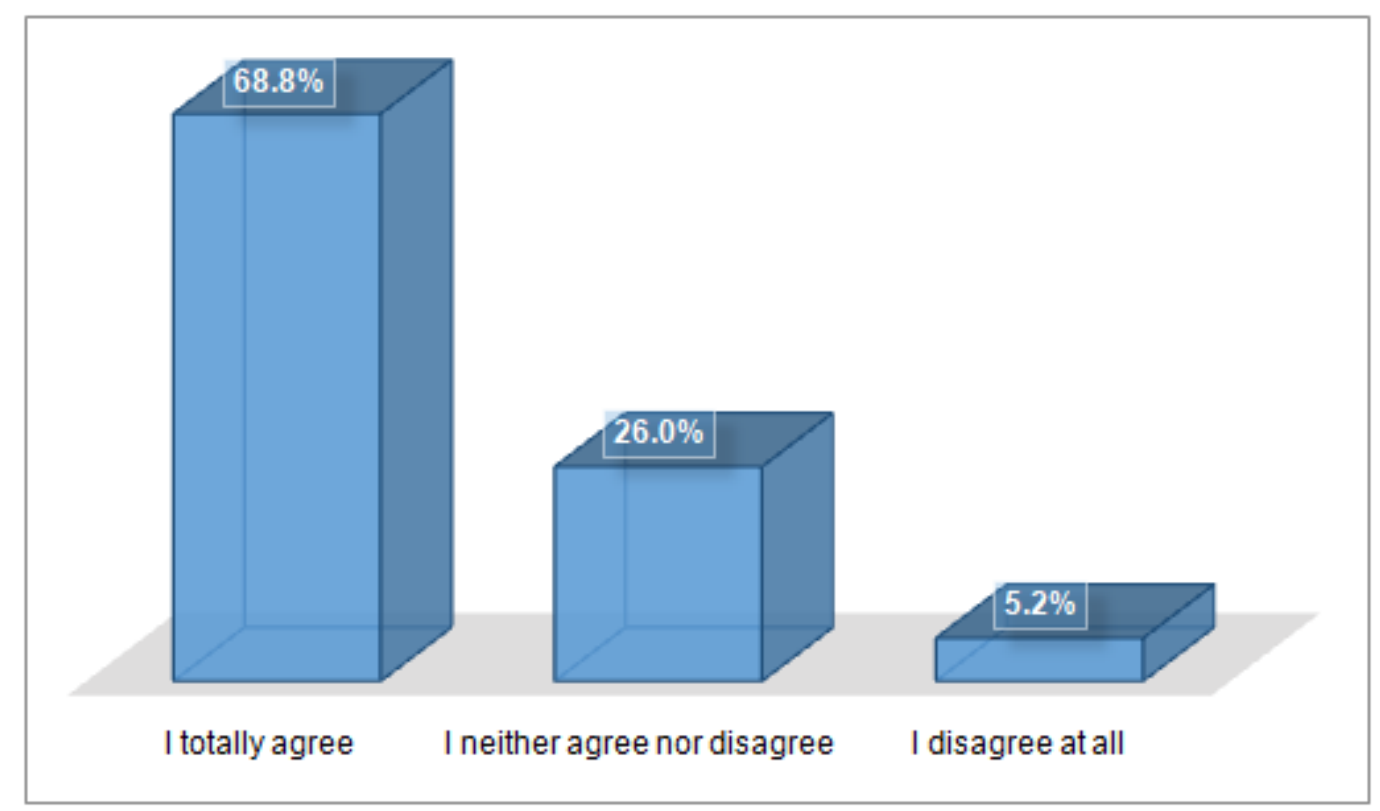

Figure10. Compared to the spring term, I conducted the autumn term distance learning much easier.

As part of the question "What was the attitude of the school management (principal) towards you during the distance learning?" The respondents were able to choose between different options. They were able to choose from several answers offered.

Figure 11 clearly shows that $18.9 \%$ of respondents chose the answer that the school management supported them at work, $10.7 \%$ of the respondents chose the answer that the school management motivated them at work, $4.9 \%$ of the respondents chose the answer that the school management imposed additional work and burdens on them, $9.1 \%$ of respondents chose the answer that the school management respected their free time, $20.9 \%$ of respondents claimed that they were regularly informed by the school management about the decisions of the Ministry of Education, Science and Sport, $17.2 \%$ of the respondents stated that the school management allowed them freedom and autonomy, $18.3 \%$ of the respondents confirmed that the school management was committed to solving their problems with technology, parents, pupils, andetcetera. 


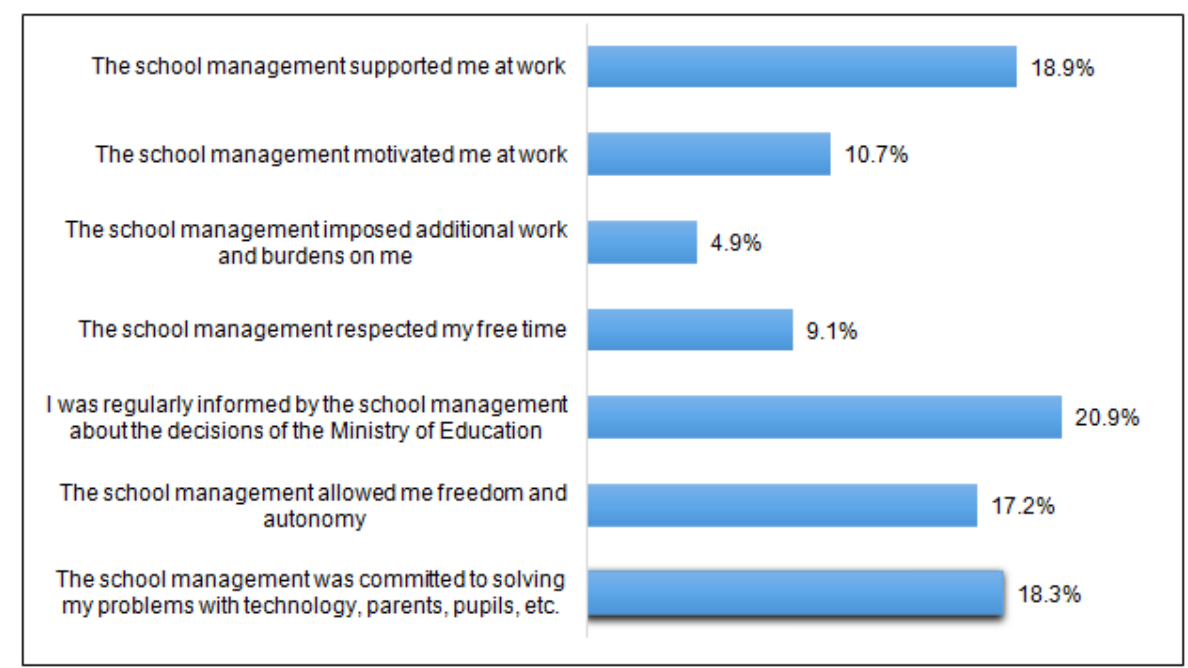

Figure11. Attitude of school management towards employees during distance learning.

To the question "How much were you burdened with distance learning compared to classroom learning?", Respondents were able to choose between grades $1-5$, with 1 meaning that they were not burdened more with distance learning, and 5 meaning that they were significantly more burdened compared to classroom learning. Grade 1 was chosen by $3.14 \%$ of respondents, $5.76 \%$ of respondents chose grade $2,14.4 \%$ of respondents chose grade $3,16.7 \%$ of respondents chose grade 4 , and grade 5 was chosen by $46.9 \%$ of respondents. The average assessment of the workload of teachers during distance learning was 4.1, which can be seen in Figure 12.

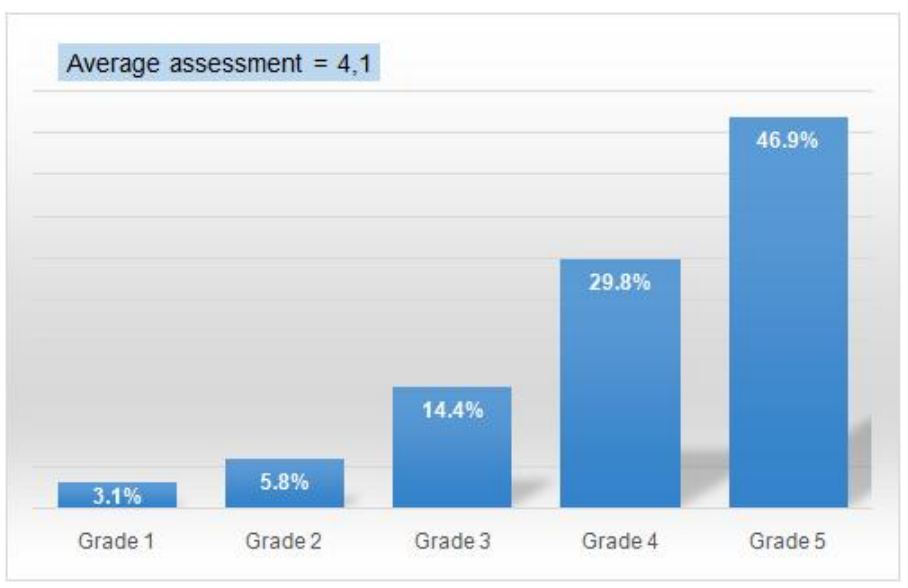

Figure12. How much were you burdened with distance learning compared to classroom learning?

Similar to the previous question, respondents answered the question "Did you experience additional efforts during distance learning compared to classroom learning?" By choosing grades from 1 to 5, with 1 meaning that they did not experience additional efforts, and 5 meaning that they experienced additional stress and strain during distance learning, the average score of the respondents was 3.8, which means that, on average, the surveyed teachers experienced additional efforts and related stress.

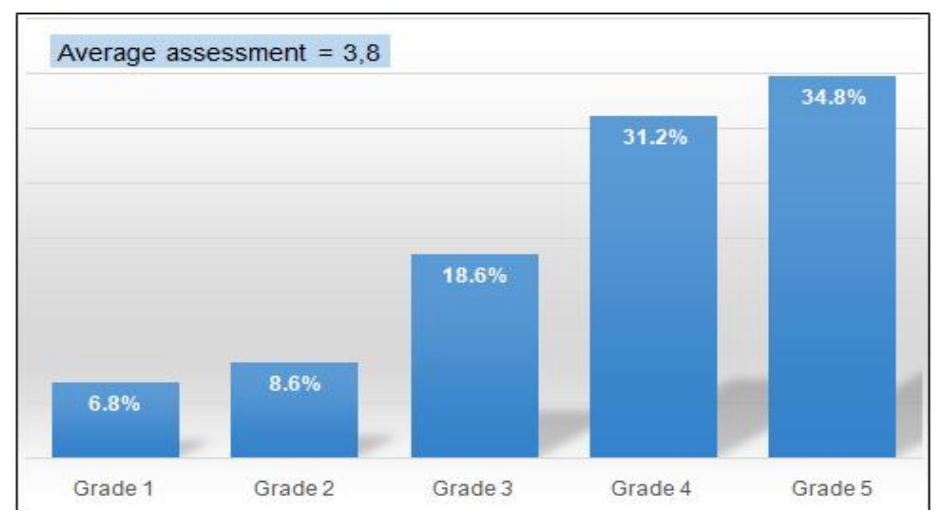

Figure13. Did you experience additional efforts during distance learning compared to classroom learning? 
To the question "What was the most frequent problem for you in distance learning?". The respondents were able to choose between different answers. It was an open-ended question, with respondents being able to write down the problems they faced in distance learning. $13.8 \%$ of respondents chose the answer that the problems were caused by the use of the selected application, $6.9 \%$ of the respondents confirmed that the problems were caused by the parents of the pupils, $26.3 \%$ of the respondents stated that the problems were caused by the pupils themselves, $7.4 \%$ of the respondents were additionally burdened by the school management, $10.5 \%$ of respondents had problems with computer equipment, $17.4 \%$ of respondents had problems with the Internet connection, $9.8 \%$ of respondents did not have adequate space for work, $8.0 \%$ of respondents pointed out other problems related to the preparation of completely new material, problems with pupils' products, older teachers encountered the challenges of modern ICT technology and the associated time they had to sacrifice to learn new online skills, etc. An interesting answer, in which probably every teacher could recognize himself, was: "Never finished a working day."

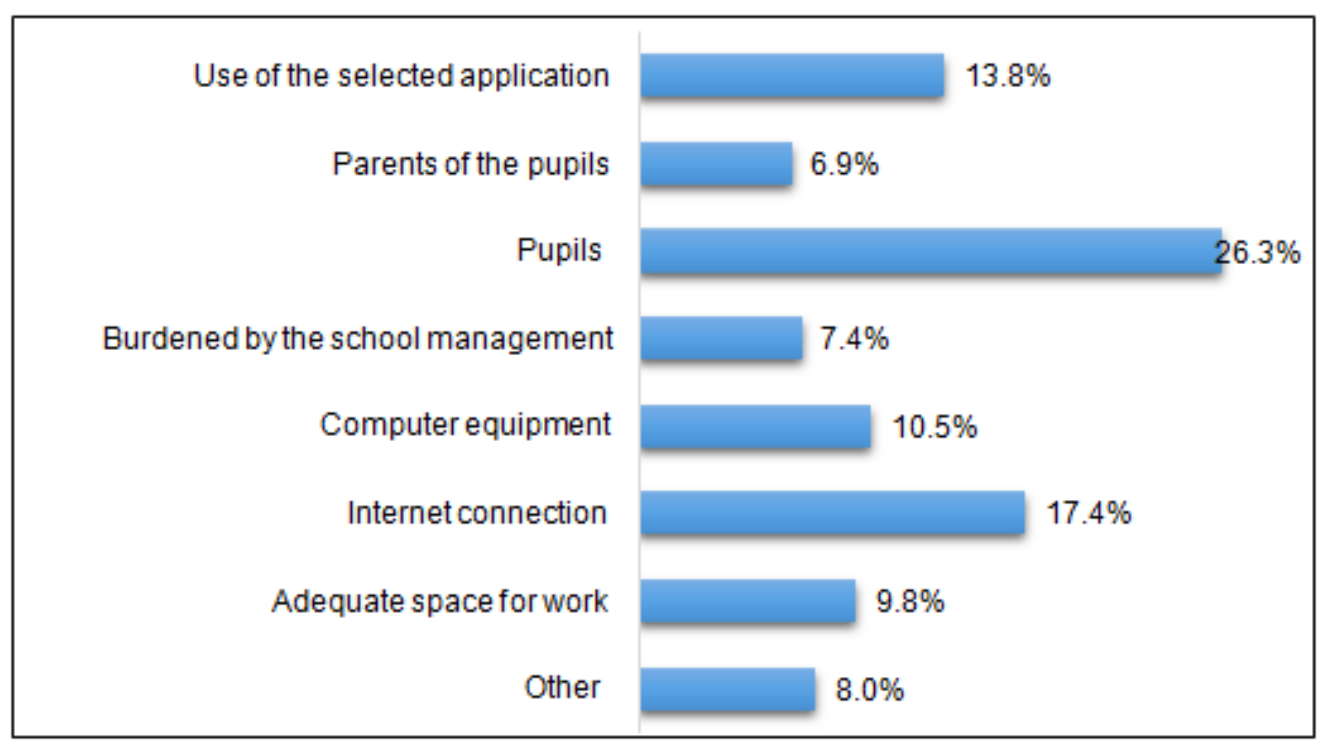

Figure14. What was the most frequent problem for you in distance learning?

\subsection{Comments, Opinions and Suggestions of the Surveyed Teachers}

225 answers to the open-ended question "What would you like to improve or change in distance learning?" were received. Here is a brief summary.

Teachers need: to be better prepared for distance learning; a serious and responsible approach by pupils and better parental control over pupils' work; a higher degree of independence and mutual participation of pupils; completed applications for testing and assessing knowledge, technical tools for distance assessment of knowledge which are not available, for example in PE classes, an application that could document the pupil's sports activities would be appropriate, and also for other subjects an application that would prevent cheating in knowledge tests and independent pupils' work. Distance learning revealed the fact that some pupils are not at all accustomed to independent work.

Among the suggestions and comments, teachers pointed out the need for: urgent changes to the curricula, as children need additional adjustments and reduction in the learning content; individual support for pupils who need it; a model for evaluating children's participation; more frequent crosscurricular connections to make the work easier for pupils and teachers; computer literacy of pupils from the first grade of primary school onwards; greater participation of teachers and exchange of preparations, exercises, assignments, quizzes, videos, i.e. materials for faster and better preparation for lessons; standardization of the number of classes for a certain subject or module at national level, not only in the context of distance learning, but also in general; elimination of unevenly spread teachers' workload; computer support for teachers by school management; reduction of the workload of pupils and teachers brought by projects; ICT trainings; advice and support in motivating pupils; specific instructions from the Ministry of Science, Education and Sports regarding those learning contents that can be omitted and those that must be improved; quality laptops, cameras and microphones; greater teacher freedom and autonomy, etc. 


\section{ANALYSIS OF TEACHER SATISFACTION AND WORKLOAD DURING DISTANCE LEARNING}

The results showed that less thana half of the respondents (42.4\%) were well prepared for distance learning, and only $61.2 \%$ of the respondents had all the computer equipment and suitable space. Less than a half of the respondents $(47.4 \%)$ can boast that they did not have any problems with the distance learning application. Less than a third of respondents (31.8\%) can claim that, despite distance learning, they managed to achieve the set learning goals. Less than a half of the respondents $(41.4 \%)$ managed to make their work easier by cooperating with other teachers, and only a third by crosscurricular connections.

Regarding the attitude of school management towards teachers during distance learning, the results do not show the best picture. Less than a fifth $(18.9 \%)$ of respondents said that the school management supported them at work, only $10.7 \%$ of respondents said that the school management motivated them at work, $4.9 \%$ of respondents stated that the management schools imposed additional work and burdens, only $9.1 \%$ of respondents said that the school management respected their free time, $17.2 \%$ of respondents felt that the school management allowed them freedom and only $18.3 \%$ of respondents said that the school management tried to solve their problems in distance learning.

The analysis showed that the teachers engaged in distance learning were much more overloaded compared to classroom learning. The average workload estimate is as high as 4.1.

The most frequent problems with distance learning were related to the pupils (26.3\%), followed by internet connection (17.4\%), distance learning applications (13.8\%), computer equipment (10.5\%), suitable space for classes $(9.8 \%)$ and the pupils' parents (6.9\%).

\section{CONCLUSION}

According to the past year experience, now it is clear to all of us that distance learning will not be a short-term activity, but at least one way of teaching in the future. This study shows that distance learning is not an "easy job". Even after the COVID-19 pandemic a lot of issue swill remain unresolved, unclear or "Proclaimed." Regardless of the fact that the classes will return to the classrooms, a lot of questions must still be answered: how to work remotely and maintain high teacher efficiency and pupil motivation, while also thinking about reducing the workload of teachers, not just pupils, as the survey showed that the teacher workload rate was as high as 4.1 on a five-point scale; how to improve support for all stakeholders in the educational process in the future, both in the field of computer training (remote work applications) and in the field of access to online interactive content; how to improve the flow of information between teachers and make better use of crosscurricular connections; how to deal with the adjustment of distance learning norms and standards; how to prepare school principals for a new way of planning and directing work, so that they will be able to respect teachers' free time, assign work tasks evenly and moderately, and maintain teachers' autonomy.

In conclusion, I would like to thank all the teachers for the time they took to answer the questionnaire, for their comments, suggestions, opinions and initiatives, without which this contribution would not be possible, as well as the principals for providing the survey to their teachers.

\section{SOURCES AND LITERATURE}

[1] Beth Pandolpho, B. (2020): Managing the Virtual and Hybrid Teaching Workload. Available at:https://www.edutopia.org/article/managing-virtual-and-hybrid-teaching-workload

[2] Schwartz, L. (2020): What Teachers in China Have Learned in the Past Month. Available at: https://www.edutopia.org/article/what-teachers-china-have-learned-past-month

[3] Terada Y. in Merrill, S. (2020): The 10 Most Significant Education Studies of 2020. Available at:https://www.edutopia.org/article/10-most-significant-education-studies-2020

\section{AUTHOR's BIOGRAPHY}

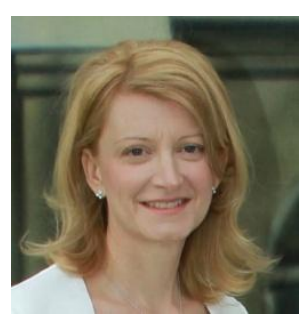

Vesna Trančar, was born in Slovenia in 1972. She is currently working at School Center Ptuj as a high school teacher of economics, marketing and entrepreneurship.

She received her $\mathrm{PhD}$ in economics and business sciences from the Faculty of Economics and Business, University of Maribor.

She is an external assessor at the vocational examination and a professional 
reviewer for higher vocational schools.

She has a headmaster's exam, a professional exam from the administrative procedure act, a professional exam in the field of education, acquired pedagogical education and certificates in the field of management.

She leads the study group for modern economy and she is a member of the state examination commission for the vocational examination.

Citation: Vesna Trančar. "Satisfaction and Workload of Slovenian Teachers during Distance Learning", International Journal of Humanities Social Sciences and Education (IJHSSE), vol 8, no. 2, 2021, pp. 216-224. doi: https://doi.org/10.20431/2349-0381.0802022.

Copyright: () 2021 Authors. This is an open-access article distributed under the terms of the Creative Commons Attribution License, which permits unrestricted use, distribution, and reproduction in any medium, provided the original author and source are credited. 